\title{
Transpulmonary gradient as a predictor for outcomes after lung transplantation
}

\author{
Ernest G. Chan^, Ankitha Madde, Masashi Furukawa, Jenalee N. Coster, John Ryan, James D. Luketich, \\ Pablo G. Sanchez
}

Department of Cardiothoracic Surgery, University of Pittsburgh Medical Center, Pittsburgh, PA, USA

Contributions: (I) Conception and design: All authors; (II) Administrative support: EG Chan, J Ryan, PG Sanchez; (III) Provision of study materials or patients: EG Chan, J Ryan, PG Sanchez; (IV) Collection and assembly of data: EG Chan, M Furukawa, J Ryan, PG Sanchez; (V) Data analysis and interpretation: EG Chan, A Madde, M Furukawa, JN Coster, J Ryan, PG Sanchez; (VI) Manuscript writing: All authors; (VII) Final approval of manuscript: All authors.

Correspondence to: Pablo G. Sanchez, MD, PhD. Associate Professor and Vice Chair, Surgical Director of Lung Transplant and ECMO, Director of Ex vivo Lung Perfusion Director of Lung Transplant Research, Department of Cardiothoracic Surgery, University of Pittsburgh, Pittsburgh, PA, USA. Email: sanchezpg@upmc.edu.

Background: End stage lung disease (ESLD) is commonly associated with pulmonary hypertension (PHTN). In a donor restrictive environment, offering patients single over double lung transplants could increase organ utilization. However, there isn't a clinical consensus on how severe PHTN must be to preclude single lung transplant (SLT) due to poor outcomes. We sought to investigate the predictive value of the transpulmonary gradient (TPG) in SLT in patients with ESLD and PHTN.

Methods: We performed a retrospective analysis of the United Network for Organ Sharing database and identified all patients who underwent lung transplantation (LT) from May 2005 to March 2021. Patients were stratified based on their TPG score above or below $25 \mathrm{mmHg}$. Primary outcomes include 1-year survival assessed by generalized linear mixed modeling.

Results: Our analysis showed TPG was associated with 1-year survival but this relationship depended on transplant type $(\mathrm{P}=0.002)$ with $\mathrm{TPG} \geq 25$ being associated with higher mortality in single $(\mathrm{P}=0.004)$, but not double LT $(\mathrm{P}=0.95)$. This association was maintained when covarying for numerous clinical factors, as well as when excluding deaths within 90 days of $\operatorname{LT}(\mathrm{P}=0.04)$.

Conclusions: A preoperative TPG >25 was associated with decreased 1-year survival in SLT recipients. The use of preoperative TPG combined with other marks of clinical status can help transplant centers in their decision of offering single vs. double lung transplant in patients with ESLD and PHTN.

Keywords: Lung transplantation (LT); single lung transplantation; transpulmonary gradient (TPG); end stage lung disease (ESLD); pulmonary hypertension (PHTN)

Received: 19 August 2021; Accepted: 02 December 2021; Published: 30 January 2022.

doi: $10.21037 /$ shc-21-22

View this article at: https://dx.doi.org/10.21037/shc-21-22

\section{Introduction}

Pulmonary hypertension (PHTN) is a progressive, and potentially fatal disease that has been shown to significantly complicate the disease course of many other chronic lung diseases (CLD) such as chronic obstructive pulmonary disease (COPD) and interstitial lung disease (ILD) (1-3). In those with more advanced disease, the prevalence of PHTN has been shown to range from $30 \%$ to as high as $85 \%$ in

^ ORCID: 0000-0001-9849-6371. 
a group of patients with ILD, and is strongly associated with an increase in morbidity and mortality (3-6). Though it is known that lung transplantation (LT) remains the only curative treatment strategy for end stage lung disease (ESLD), particularly in the setting of refractory disease despite optimal medical therapy, the choice of procedure (single $v s$. bilateral LT) is still an open debate. For both end stage COPD and ILD, the recent trend favors bilateral lung transplants (BLT) over single lung transplants (SLT), citing improved lung function and superior survival rates as the primary outcomes $(7,8)$. Though a mortality benefit might be apparent, emphasis on BLT has unfortunately led to a significant transplant limitation and outcomes in this group are further hindered by a very high waiting list mortality (12\% and $20 \%$ for COPD and ILD respectively) (9).

SLT proponents cite the simpler technical nature, shorter duration, and quicker recovery as advantages, and many studies have found equivocal or increased short term survival outcomes when compared to BLT. Meyer et al., one of the first to use UNOS data to study outcomes in SLT vs. BLT, found similar 1-month and 1-year survival rates in patients with COPD but reduced 5-year survival, and found better 1-month and 3-year survival rates in patients with ILD $(10,11)$. Likewise, survival outcomes in the International Society for Heart and Lung Transplantation (ISHLT) registry report in 2019 showed similar 1-year survival rates for patients with ILD and COPD however significantly reduced long term survival in SLT $v s$. BLT recipients (12). The equivalent short-term outcomes suggest that SLT should still be considered a viable transplant option, but to provide equivalent long term benefit as well, careful patient selection via disease stratification should be employed to find those with the best chance of survival.

The preoperative workup of patients with ESLD includes many physiologic parameters to help stratify the severity of disease. Transpulmonary gradient (TPG) is defined as the difference between mean pulmonary arterial pressure (mPAP) and left atrial pressure (Pla), which is usually estimated by mean pulmonary capillary wedge pressure (mPCWP) (13). PHTN due to ESLD is precipitated by alveolar hypoxia leading to pulmonary vasoconstriction and intrinsic vascular remodeling, thus TPG was chosen as it is highly dependent on vascular resistance $(14,15)$. Furthermore, TPG measures are more suitable than the traditional pulmonary artery pressures to characterize PHTN secondary to ESLD due to their independence from factors such as flow, inertia, vascular compliance, and alveolar pressures (16). A TPG value $>12-15$ is generally associated with a diagnosis of PHTN, and an increase in this value is correlated with an increase in the precapillary stiffness of the pulmonary vasculature indicating a higher severity of lung disease (13). Currently, there is no consensus regarding the use of parameters such as TPG to guide the decision making for the type of LT in patients with ESLD. We predict a TPG greater than $25 \mathrm{mmHg}$ will be associated with poor outcomes following single LT. Therefore, the goal of this study is to investigate the use of TPG as a predictor of outcomes following SLT $v$ s. BLT in patients with ESLD. We present the following article in accordance with the STROBE reporting checklist (available at https://shc. amegroups.com/article/view/10.21037/shc-21-22/rc).

\section{Methods}

\section{Patients}

We performed a retrospective analysis using the United Network of Organ Sharing (UNOS) Standard Analysis and Research (STAR) database based on OPTN data as of March 5, 2021. Adult patients ( $\geq 18$ years old) who underwent a primary LT between May 4, 2005 and March 3, 2021 were included. Patients undergoing a re-do transplant or multiorgan transplant were excluded, as well as patients with a diagnosis of primary PHTN or suppurative disease (UNOS diagnosis groups "B" and "C"). TPG was calculated by subtracting mPCWP from mPAP at time of transplant. TPG dichotomization was a consensus within the surgical team and based on clinical practice. The study was conducted in accordance with the Declaration of Helsinki (as revised in 2013). The study was approved by institutional review board of The University of Pittsburgh School of Medicine and individual consent for this retrospective analysis was waived.

\section{Outcomes}

The primary outcome was 1-year survival. Secondary outcomes of interest included post-operative length of stay, long term survival ( 3 and 5 years), and pre-discharge complications including airway dehiscence, stroke, and dialysis. Additional variables that were investigated include patient demographics (age, gender, body mass index, etc.), preoperative kidney function, different types of pulmonary disease, and preoperative pulmonary function.

\section{Statistical analysis}

Univariate analyses were performed with Mann-Whitney U 
Table 1 Patient characteristics stratified by transpulmonary gradient (TPG) above or below $25 \mathrm{mmHg}$

\begin{tabular}{|c|c|c|c|c|}
\hline Variable & Total cohort $(n=22,881)$ & TPG $<25(n=19,731)$ & $T P G \geq 25(n=3,150)$ & $\mathrm{P}$ \\
\hline Age (years), mean (SD) & $59.65(9.5)$ & $59.97(9.4)$ & $57.70(10.0)$ & $<0.001$ \\
\hline Body mass index $\left(\mathrm{kg} / \mathrm{m}^{2}\right)$, mean (SD) & $26.03(4.3)$ & $26.07(4.3)$ & $26.62(4.3)$ & $<0.001$ \\
\hline Serum creatinine, mean (SD) & $0.87(0.4)$ & $0.86(0.41)$ & $0.89(0.41)$ & $<0.001$ \\
\hline Lung allocation score, mean (SD) & $47.44(17.7)$ & $45.73(16.7)$ & $58.08(34.7)$ & $<0.001$ \\
\hline Systolic PAP (mmHg), mean (SD) & $41.41(15.0)$ & $37.33(9.8)$ & $67.03(16.1)$ & $<0.001$ \\
\hline Diastolic PAP (mmHg), mean (SD) & $17.21(8.4)$ & $15.36(6.5)$ & $28.82(9.6)$ & $<0.001$ \\
\hline Mean PAP (mmHg), mean (SD) & $26.51(9.9)$ & $23.81(6.6)$ & $43.46(10.3)$ & $<0.001$ \\
\hline Male, n (\%) & $14,191(62.0)$ & $12,217(61.9)$ & $1,974(62.7)$ & 0.42 \\
\hline \multicolumn{5}{|l|}{ Diagnosis, n (\%) } \\
\hline Obstructive & $7,491(32.7)$ & $6,980(35.4)$ & $511(16.2)$ & $<0.001$ \\
\hline Restrictive & $15,390(67.3)$ & $12,751(64.6)$ & $2,639(83.8)$ & \\
\hline Diabetes, n (\%) & 3,791 (16.6) & $3,168(16.1)$ & $623(19.8)$ & $<0.001$ \\
\hline \multicolumn{5}{|l|}{ Transplant type, n (\%) } \\
\hline Single & 7,841 (34.3) & $7,312(37.1)$ & $529(16.8)$ & $<0.001$ \\
\hline ECMO bridge, n (\%) & $720(3.2)$ & $524(2.7)$ & $196(6.3)$ & $<0.001$ \\
\hline
\end{tabular}

BMI, body mass index; PAP, pulmonary artery pressure; PCWP, pulmonary capillary wedge pressure; FEV1, forced expiratory volume in one minute; HTN, hypertension.

tests for continuous variables, and chi squares for categorical data. Relationships between TPG and one-year survival were modeled using generalized linear mixed models with a binomial distribution and logit link (17). TPG and transplant type were entered as fixed effects, transplant center as a random effect, and survival as a binarized outcome. Covariates included recipient age, donor sex, diagnosis group, body mass index, transplant type (single or double), LAS at the time of transplant, ischemic time lung allocation score (LAS), transplant type, total bilirubin, medical condition at time of transplant (home, hospitalized, or
hospitalized-ICU), ventilator status at time of match, and ECMO status at time of match. Univariable analyses were performed using SPSS (v. 27, IBM Corp., Armonk, NY, USA) and KaplanMeier and multivariable analyses were performed using $\mathrm{R}$ (v. 4.0.3) with packages "survival" and "GLMMAdaptive". A $\mathrm{P}<0.05$ was considered statistically significant.

\section{Results}

A total of 22,881 patients underwent LT between May 2005 
Table 2 Donor characteristics stratified by recipient TPG above or below $25 \mathrm{mmHg}$

\begin{tabular}{|c|c|c|c|c|}
\hline Variable & Total cohort & TPG $<25$ & $\mathrm{TPG} \geq 25$ & $\mathrm{P}$ \\
\hline Body Mass Index $\left(\mathrm{kg} / \mathrm{m}^{2}\right)$, mean (SD) & $26.29(5.5)$ & $25.39(5.5)$ & $26.47(5.9)$ & 0.35 \\
\hline $\mathrm{pO}_{2}$, mean (SD) & $381.37(143.3)$ & $418.0(143.2)$ & $383.06(143.6)$ & 0.48 \\
\hline $\mathrm{pCO}_{2}$, mean $(\mathrm{SD})$ & $37.18(6.7)$ & $37.22(6.8)$ & $36.92(6.4)$ & 0.09 \\
\hline Ischemic time (hours), mean (SD) & $5.29(2.0)$ & $5.24(2.0)$ & $5.60(1.9)$ & $<0.001$ \\
\hline Male, n (\%) & $13,934(60.9)$ & $12,165(61.7)$ & $1,769(56.2)$ & $<0.001$ \\
\hline History of HTN, n (\%) & $5,455(23.8)$ & $4,729(24.0)$ & $726(23.0)$ & 0.53 \\
\hline History of diabetes, n (\%) & $1,730(7.6)$ & $1,506(7.6)$ & $224(7.1)$ & 0.17 \\
\hline
\end{tabular}

TPG, transpulmonary gradient; LV, left ventricle; HTN, hypertension; CDC, Centers for Disease Control.

and March 2021 who met inclusion and exclusion criteria. Table 1 details the recipient characteristics. Patients with TPG $\geq 25 \mathrm{mmHg}$ had a shorter waitlist time $(\mathrm{P}<0.001)$, younger age $(\mathrm{P}<0.001)$, higher $\mathrm{BMI}(\mathrm{P}<0.001)$, higher serum creatinine $(\mathrm{P}<0.001)$ and bilirubin $(\mathrm{P}<0.001)$, and higher LAS $(\mathrm{P}<0.001)$. Patients with $\mathrm{TPG} \geq 25 \mathrm{mmHg}$ also had higher systolic $(\mathrm{P}<0.001)$, diastolic $(\mathrm{P}<0.001)$, and mean PAP $(\mathrm{P}<0.001)$ and FEV1 $(\mathrm{P}<0.001)$, and were more likely to have received bilateral LT over single LT $(\mathrm{P}<0.0001)$. Patients with PGD $\geq 25 \mathrm{mmHg}$ were more likely to have a diagnosis of restrictive disease $(\mathrm{P}<0.001)$, were more likely to be hospitalized at time of transplant $(\mathrm{P}<0.001)$ and were more likely to be on mechanical ventilation or ECMO as a bridge to transplant $(\mathrm{P}<0.001)$.

\section{Donor characteristics}

Donor information is displayed in Table 2. There were no differences between TPG groups in donor age $(\mathrm{P}=0.76)$, BMI $(\mathrm{P}=0.35)$, and cardiac ejection fraction $(\mathrm{P}=0.70)$. However, patients with TPG $\geq 25 \mathrm{mmHg}$ were more likely to receive donor lungs from a female donor $(\mathrm{P}<0.001)$ and receive lungs with longer ischemic times $(\mathrm{P}<0.001)$.

\section{Post-operative outcomes}

Table 3 summarizes post-operative and survival outcomes. Following surgery, patients with TPG $\geq 25$ had longer length of stay $(\mathrm{P}<0.0001)$, increased incidence of airway dehiscence $(\mathrm{P}=0.02)$, and were more likely to receive postoperative dialysis $(\mathrm{P}<0.001)$. There was no difference in the incidence of post-operative stroke between TPG groups $(\mathrm{P}=0.46)$. Patients with $\mathrm{TPG} \geq 25 \mathrm{mmHg}$ had a lower one-year survival $(\mathrm{P}<0.001)$ (Figure 1$)$. However, this difference was eliminated at three-year $(\mathrm{P}=0.43)$ and 5 -years $(\mathrm{P}=0.61)$ post-transplant.

\section{Multivariable analyses}

Generalized mixed-effects analyses were conducted to examine the relationship between TPG, transplant type (single or double) and one-year survival. In a multivariable analysis, TPG category $(\mathrm{P}<0.001)$ was significantly associated with one-year survival, but this relationship was qualified with a significant transplant type by TPG interaction $(\mathrm{P}<0.001)$ indicating that the relationship between TPG and survival differed by transplant type (Table 4). To probe the interaction, the data were stratified by transplant type. In single LT recipients, TPG $\geq 25$ remained a significant predictor of one-year survival $(\mathrm{P}=0.004)$, but this relationship was not present for double LT recipients $(\mathrm{P}=0.95)$. Regardless of transplant type, older age, being in the ICU, or on a ventilator at time of match were associated with increased risk of one-year mortality. In single-lung recipients, being hospitalized (non-ICU) was associated with increased risk of one-year mortality (Table 4). Double lung recipients with a restrictive lung disease (relative to obstructive) as well as those with longer ischemic times were at increased risk of one-year mortality (Table 4).

Within single LT, 479 (5.6\%) died within 90 days of 
Table 3 Postoperative outcomes

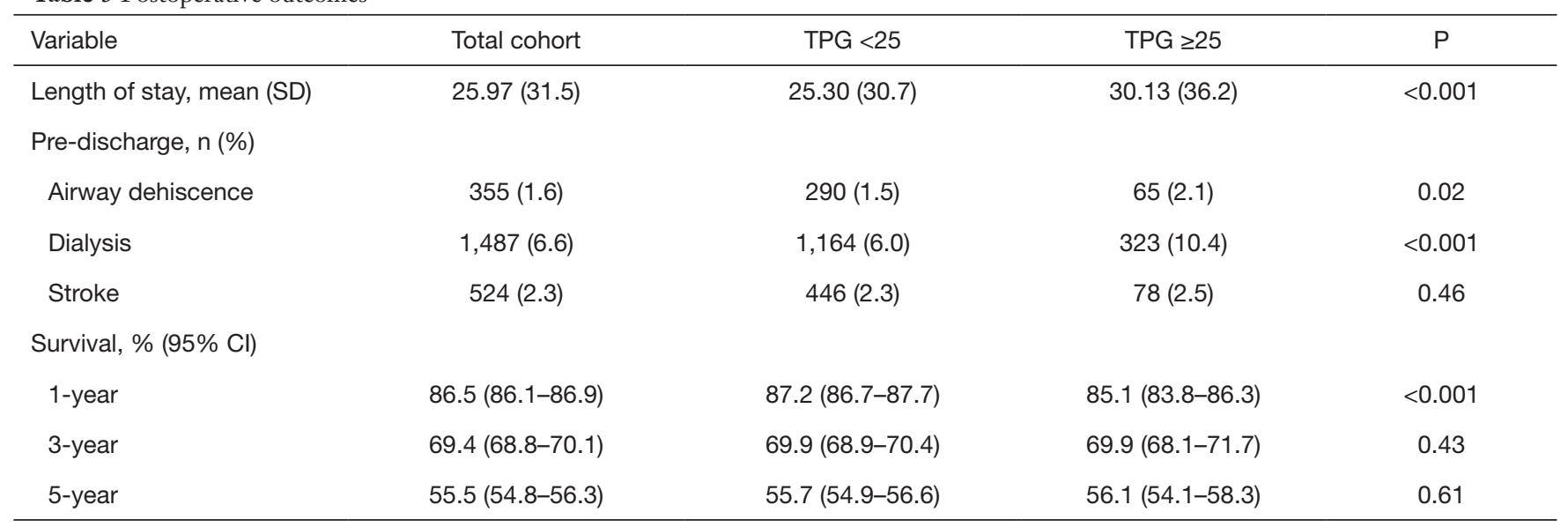

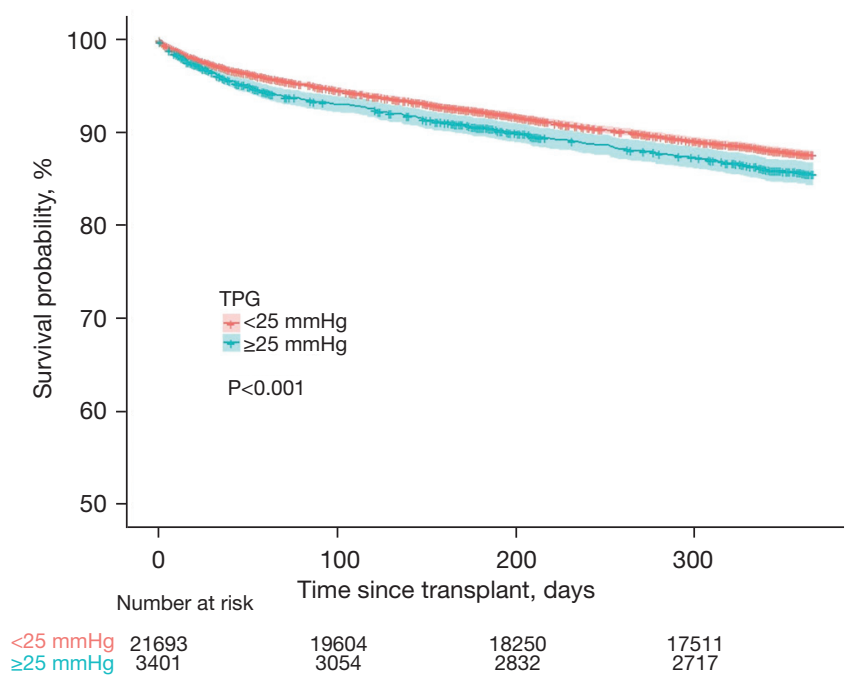

Figure 1 Patients with TPG $\geq 25 \mathrm{mmHg}$ had a lower one-year survival $(\mathrm{P}<0.001)$.

transplant. To examine the relationship between TPG and one-year survival, but excluding deaths related to surgical complications, we repeated the multivariable analysis, but excluded patients who died within the 90-day post-transplant period. In this analysis, $\mathrm{TPG} \geq 25 \mathrm{mmHg}$ remained a significant predictor of one-year survival (Table 5). Older age, having higher bilirubin levels, being in the ICU or hospitalized at time of match were additional significant predictors of one-year mortality.

\section{Discussion}

Although overall waitlist mortality has decreased for most diagnoses of ESLD since the implementation of the LAS system, waitlist mortality in patients is still high, especially those with restricted listing preferences $(9,18)$. In a recent study by Anderson et al. looking at 14,000 patients with COPD or ILD, they found nearly $25 \%$ of patients listed for BLT were not transplanted due to death and other outcomes. Furthermore, their adjusted analyses identified a decreased risk of death as well as comparable 1-year and 5 -year graft survival rates for unrestricted $v s$. restricted listings, showing the utility of allowing patients to undergo SLT whenever possible (9).

The majority of the current literature supports preferred use of BLT over SLT for secondary PHTN as it has been shown to be associated with a better long-term survival (19). However, one limitation of many of these studies is the lack of quantifying severity of disease. Huerd et al. reported outcomes after SLT for moderate PHTN defined as MPAP $30-40 \mathrm{mmHg}$ and found overall successful outcomes in early and late allograft function with acceptable long term overall survival (20). Fitton et al. also found survival to be equivalent with mild/moderate PHTN (vs. severe PHTN) in both SLT and BLT, concluding that SLT is an acceptable transplantation option (21). Finally, a recent 2019 study which looked at PHTN stratified by mPAP ( $<40$ vs. $\geq 40 \mathrm{mmHg}$ ) also found those who underwent SLT with mPAP $<40 \mathrm{mmHg}$ to have a higher long-term survival compared to those with $\mathrm{mPAP} \geq 40 \mathrm{mmHg}$, further offering evidence that SLT in mild/moderate PHTN is acceptable (22).

Our current study similarly looked at the outcome and survival differences between SLT and BLT in the setting of secondary PHTN when stratifying by disease 
Table 4 Multivariable mixed-effects models: relationship between TPG above or below $25 \mathrm{mmHg}$ and one-year survival based on type of lung transplant

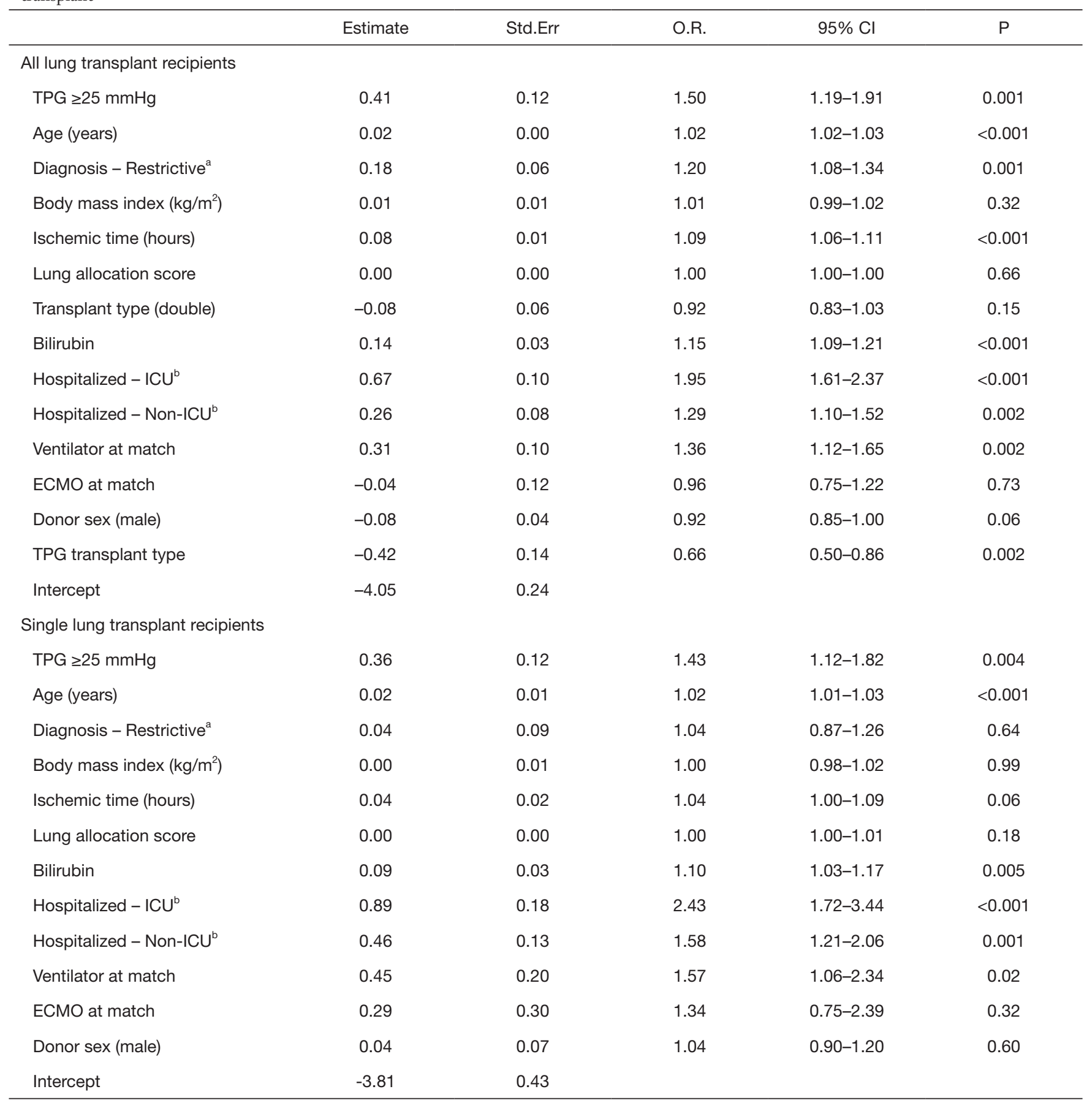

Table 4 (continued) 
Table 4 (continued)

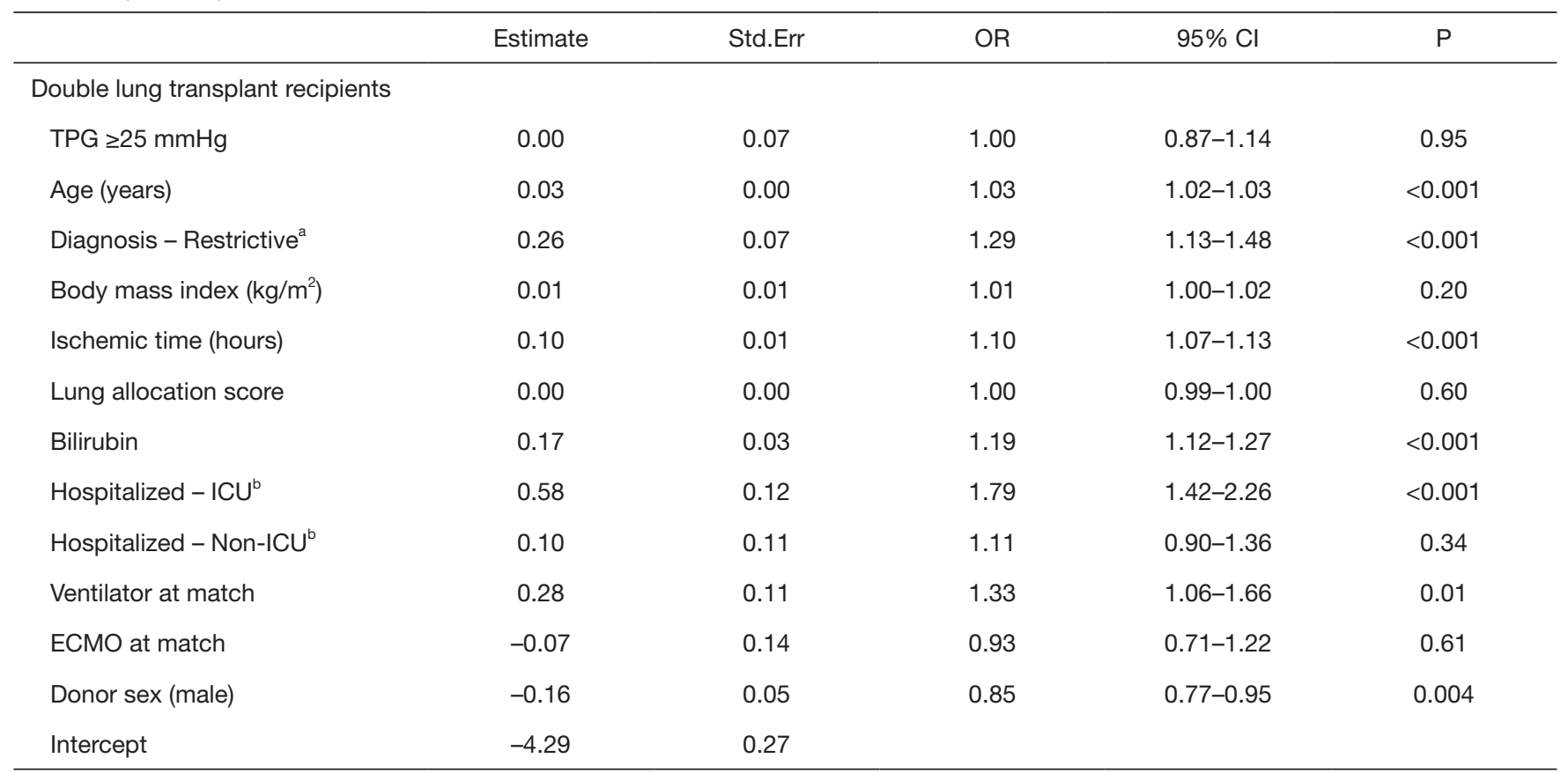

${ }^{a}$, reference group: obstructive lung disease; ${ }^{b}$, reference group: non-hospitalized. TPG, transpulmonary gradient, HTN, hypertension.

Table 5 Multivariable mixed-effects model: relationship between TPG above or below $25 \mathrm{mmHg}$ and one-year survival in single-lung recipients excluding patients who died within 90 days of transplant

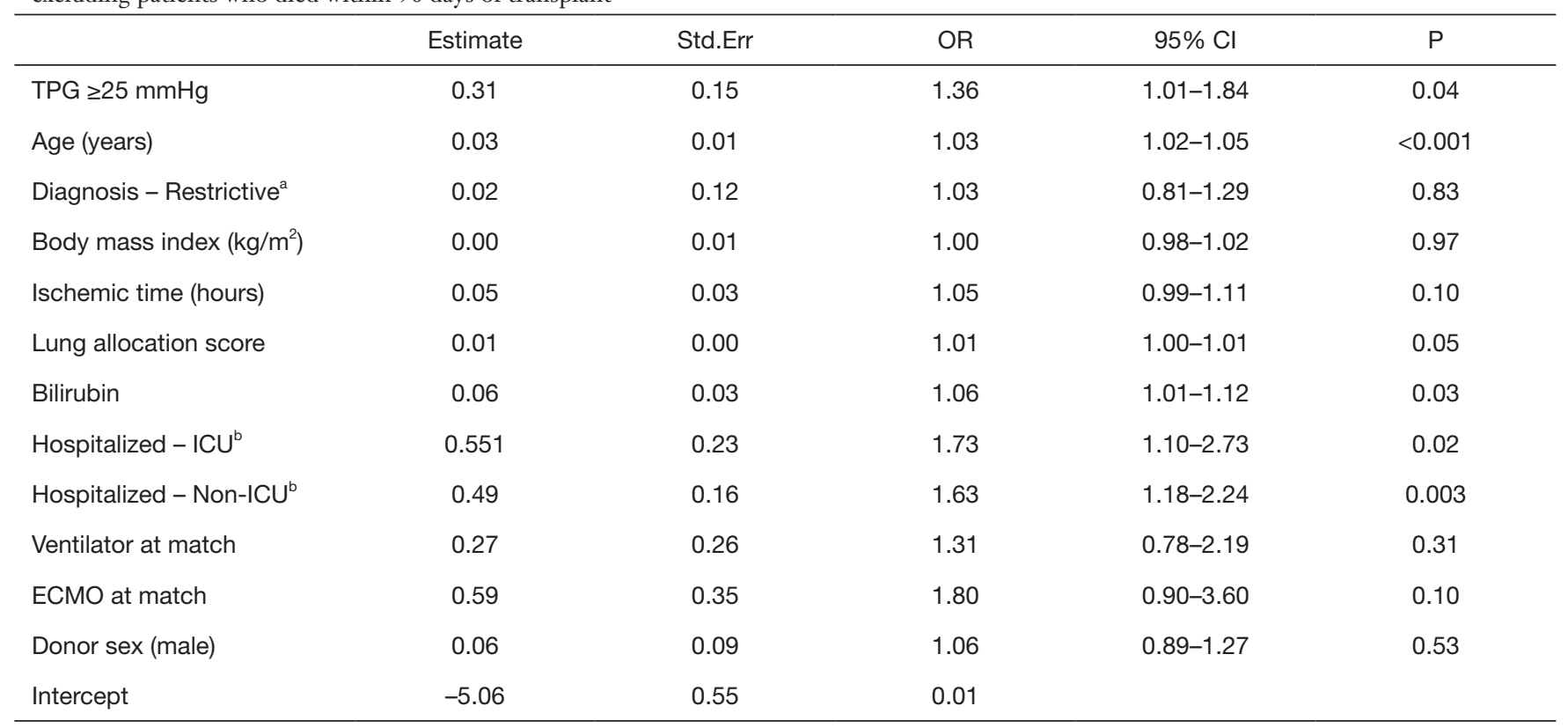

a, reference group: obstructive lung disease; ${ }^{b}$, reference group: non-hospitalized. TPG, transpulmonary gradient, HTN, hypertension. 
severity defined by TPG. When analyzing patients undergoing SLT, we found patients with more severe PHTN defined as a TPG $\geq 25 \mathrm{mmHg}$ were associated with a longer postoperative course and higher postoperative complications, such as airway dehiscence, dialysis and stroke. On multivariable analysis, age, LAS at transplant, ischemic time, transplant type, and TPG $\geq 25 \mathrm{mmHg}$ were all independent predictors of 1-year survival, however when separating by the type of transplant, TPG $\geq 25 \mathrm{mmHg}$ was independently associated with reduced survival only in SLT recipients.

Furthermore, TPG $\geq 25 \mathrm{mmHg}$ was found to be independently associated with an increased hazard of 1-year mortality in SLT. The association remained significant even after excluding patients who died within 90 days of transplant. However, differences in survival were eliminated at longer follow-up times (3+ years). These results may indicate that complications associated with severe PHTN and LT may occur in the early postoperative period. With proper postoperative care, once patients are ushered out of this early window of increased morbidity and mortality, long term outcomes may not be compromised. Ultimately, additional studies are needed to further elicit the relationship between TPG and outcomes following SLT in patients with PHTN.

There are a number of limitations that should be highlighted. First, this is a retrospective study and therefore the results are subjected to reporter and recall bias. Second, this is an analysis of a nationally collected dataset and therefore the results of our study are reliant on the quality of its data. Therefore, though it contains extensive patientlevel data on LT in the past couple decades, it is also subject to its limitations including but not restricted to data entry errors, and missing data. Specifically, some important results which are not included in the database but would provide additional insight into the current topic are postoperative quality of life measures, allograft function, rates of rejection, and donor lung hemodynamic measures. Furthermore, our use of the TPG values were limited as well. Nonetheless, this is a high-powered study as one of the first to evaluate the role of TPG in predicting post-transplant mortality, and thus still provides valuable results.

In conclusion, elevated TPG is a significant predictor of decreased post-transplant long-term survival in SLT recipients but not BLT recipients. This may indicate that efforts in minimizing the severity of PHTN can be associated with better outcomes after SLT, and specifically promotes the use of TPG as a prognostic factor in predicting SLT post-transplant mortality rates.

\section{Acknowledgments}

The data reported here have been supplied by UNOS as the contractor for the OPTN. The interpretation and reporting of these data are the responsibility of the study authors and in no way should be seen as official policy of or interpretation by the OPTN or the US Government.

Funding: None.

\section{Footnote}

Reporting Checklist: The authors have completed the STROBE reporting checklist. Available at https://shc. amegroups.com/article/view/10.21037/shc-21-22/rc

Peer Review File: Available at https://shc.amegroups.com/ article/view/10.21037/shc-21-22/prf

Conflicts of Interest: All authors have completed the ICMJE uniform disclosure form (available at https://shc.amegroups. com/article/view/10.21037/shc-21-22/coif). PGS serves as an unpaid editorial board member of Shanghai Chest from June 2021 to May 2023. The other authors have no conflicts of interest to declare.

Ethical Statement: The authors are accountable for all aspects of the work in ensuring that questions related to the accuracy or integrity of any part of the work are appropriately investigated and resolved. The study was conducted in accordance with the Declaration of Helsinki (as revised in 2013). The study was approved by institutional review board of The University of Pittsburgh School of Medicine and individual consent for this retrospective analysis was waived.

Open Access Statement: This is an Open Access article distributed in accordance with the Creative Commons Attribution-NonCommercial-NoDerivs 4.0 International License (CC BY-NC-ND 4.0), which permits the noncommercial replication and distribution of the article with the strict proviso that no changes or edits are made and the original work is properly cited (including links to both the 
formal publication through the relevant DOI and the license). See: https://creativecommons.org/licenses/by-nc-nd/4.0/.

\section{References}

1. Nathan SD, Barbera JA, Gaine SP, et al. Pulmonary hypertension in chronic lung disease and hypoxia. Eur Respir J 2019;53:1801914.

2. Medrek SK, Sharafkhaneh A, Spiegelman AM, et al. Admission for COPD Exacerbation Is Associated with the Clinical Diagnosis of Pulmonary Hypertension: Results from a Retrospective Longitudinal Study of a Veteran Population. COPD 2017;14:484-9.

3. Hayes D Jr, Black SM, Tobias JD, et al. Influence of Pulmonary Hypertension on Patients With Idiopathic Pulmonary Fibrosis Awaiting Lung Transplantation. Ann Thorac Surg 2016;101:246-52.

4. Nadrous HF, Pellikka PA, Krowka MJ, et al. The impact of pulmonary hypertension on survival in patients with idiopathic pulmonary fibrosis. Chest 2005;128:616S-7S.

5. Shorr AF, Wainright JL, Cors CS, et al. Pulmonary hypertension in patients with pulmonary fibrosis awaiting lung transplant. Eur Respir J 2007;30:715-21.

6. Andersen KH, Iversen M, Kjaergaard J, et al. Prevalence, predictors, and survival in pulmonary hypertension related to end-stage chronic obstructive pulmonary disease. J Heart Lung Transplant 2012;31:373-80.

7. Yusen RD, Edwards LB, Dipchand AI, et al. The Registry of the International Society for Heart and Lung Transplantation: Thirty-third Adult Lung and HeartLung Transplant Report-2016; Focus Theme: Primary Diagnostic Indications for Transplant. J Heart Lung Transplant 2016;35:1170-84.

8. Stehlik J, Edwards LB, Kucheryavaya AY, et al. The Registry of the International Society for Heart and Lung Transplantation: Twenty-eighth Adult Heart Transplant Report--2011. J Heart Lung Transplant 2011;30:1078-94.

9. Anderson MR, Tabah A, RoyChoudhury A, et al. Procedure Preference and Intention-to-Treat Outcomes after Listing for Lung Transplantation among U.S. Adults. A Cohort Study. Ann Am Thorac Soc 2019;16:231-9.

10. Meyer DM, Bennett LE, Novick RJ, et al. Single vs bilateral, sequential lung transplantation for end-stage emphysema: influence of recipient age on survival and secondary end-points. J Heart Lung Transplant
2001;20:935-41.

11. Meyer DM, Edwards LB, Torres F, et al. Impact of recipient age and procedure type on survival after lung transplantation for pulmonary fibrosis. Ann Thorac Surg 2005;79:950-7; discussion 957-8.

12. Chambers DC, Cherikh WS, Harhay MO, et al. The International Thoracic Organ Transplant Registry of the International Society for Heart and Lung Transplantation: Thirty-sixth adult lung and heartlung transplantation Report-2019; Focus theme: Donor and recipient size match. J Heart Lung Transplant. 2019;38(10):1042-55.

13. Naeije R, Vachiery JL, Yerly P, et al. The transpulmonary pressure gradient for the diagnosis of pulmonary vascular disease. Eur Respir J 2013;41:217-23.

14. Sajkov D, Mupunga B, Bowden JJ, et al. Pulmonary Hypertension in Chronic Lung Diseases and/or Hypoxia. In: Elwing JM, Panos RJ. editors. Pulmonary Hypertension. IntechOpen, 2013. doi: 10.5772/55681.

15. Chemla D, Castelain V, Hervé P, et al. Haemodynamic evaluation of pulmonary hypertension. Eur Respir J 2002;20:1314-31.

16. Singh VK, Patricia George M, Gries CJ. Pulmonary hypertension is associated with increased post-lung transplant mortality risk in patients with chronic obstructive pulmonary disease. J Heart Lung Transplant 2015;34:424-9.

17. Hox JJ, Moerbeek M, van de Schoot R. Multilevel Analysis: Technques and Applications. New York: Routledge Taylor \& Francis Group, 2018.

18. Chen H, Shiboski SC, Golden JA, et al. Impact of the lung allocation score on lung transplantation for pulmonary arterial hypertension. Am J Respir Crit Care Med 2009;180:468-74.

19. Chambers DC, Yusen RD, Cherikh WS, et al. The Registry of the International Society for Heart and Lung Transplantation: Thirty-fourth Adult Lung And HeartLung Transplantation Report-2017; Focus Theme: Allograft ischemic time. J Heart Lung Transplant 2017;36:1047-59.

20. Huerd SS, Hodges TN, Grover FL, et al. Secondary pulmonary hypertension does not adversely affect outcome after single lung transplantation. J Thorac Cardiovasc Surg 2000;119:458-65.

21. Fitton TP, Kosowski TR, Barreiro CJ, et al. Impact of 
secondary pulmonary hypertension on lung transplant outcome. J Heart Lung Transplant 2005;24:1254-9.

22. Nasir BS, Mulvihill MS, Barac YD, et al. Single lung transplantation in patients with severe secondary pulmonary hypertension. J Heart Lung Transplant 2019;38:939-48.

doi: $10.21037 /$ shc-21-22

Cite this article as: Chan EG, Madde A, Furukawa M, Coster JN, Ryan J, Luketich JD, Sanchez PG. Transpulmonary gradient as a predictor for outcomes after lung transplantation. Shanghai Chest 2022;6:2. 